\title{
A Antropologia e o advento da Fertilização In Vitro no Reino Unido: uma história curta*
}

Marilyn Strathern $^{* *}$

\section{Resumo}

O ano de 2009 marcou o quadragésimo aniversário de um texto pioneiro que apareceu na revista inglesa Nature e que pressagiava $\mathrm{o}$ advento de procedimentos bem sucedidos de Fertilização in Vitro e de muito mais. Esse foi o tema de uma conferência reunida sob o título "Embriões Humanos in Vitro: reflexões interdisciplinares sobre as primeiras quatro décadas". Meu trabalho era simplesmente chamado de "A Visão da Antropologia Social", sua "obra" básica está na bibliografia anexa. Ele se refere a desenvolvimentos no mundo de fala inglesa, mas espero que seja de interesse mais amplo.

Palavras-chave: Fertilização in vitro, Tecnologias de Reprodução Assistida, Parentesco, Antropologia.

\footnotetext{
" Recebido para publicação em outubro de 2009, aceito em novembro de 2009. Agradeço a Jeanette Edwards, Sarah Franklin e Merve Demircioglu por seus comentários a esta versão, que muito me ajudaram, $e$ a suas sugestões bibliográficas. $\mathrm{O}$ trabalho foi apresentado primeiro numa conferência de um dia, In Vitro Human Embryos, organizada por Martin Johnson, Sarah Franklin e Nick Hopwood, Cambridge, em fevereiro de 2009, e subsequentemente apresentado no Núcleo de Estudos de Gênero - Pagu/Unicamp, em outubro de 2009, onde agradeço a Mariza Corrêa e Adriana Piscitelli por sua hospitalidade. Apreciei o estímulo nas duas ocasiões. O Núcleo de Estudos de Gênero - Pagu agradece o apoio do Departamento de Antropologia e do Doutorado em Ciências Sociais, ambos do Instituto de Filosofia e Ciências Humanas da Unicamp, ao seminário de Marilyn Strathern, que tornou sua palestra acessível a um número maior de estudantes [Tradução: Plínio Dentzien].
}

** Antropóloga, Universidade de Cambridge.ms10026@cam.ac.uk 
Anthropology and the Advent of IVF in the UK:

a Short Story

\begin{abstract}
The year 2009 marked the $40^{\text {th }}$ anniversary of a ground-breaking paper that appeared in the UK journal Nature that presaged the advent of successful IVF procedures, and much else. This was the subject of a conference held under the title "In vitro human embryos: Interdisciplinary reflections on the first four decades". My paper was simply called "The view from social anthropology", the basic "work" of the paper being in the accompanying bibliography. It concerns developments in the English-speaking world, but hopefully is of wider interest.
\end{abstract}

Key Words: IVF, New Reproductive Tecnologies, Kinship, Anthropology. 
Preâmbulo. O ano de 2009 marcou o quadragésimo aniversário de um texto pioneiro que apareceu na revista inglesa Nature e que pressagiava o advento de procedimentos bem sucedidos de Fertilização in Vitro e de muito mais. Esse foi o tema de uma conferência reunida sob o título "Embriões Humanos in Vitro: reflexões interdisciplinares sobre as primeiras quatro décadas". A questão posta era que diferença esse texto fez para diversas disciplinas - ética, direito, medicina, biologia, artes visuais e antropologia social. Meu trabalho era simplesmente chamado de "A Visão da Antropologia Social", sua "obra" básica está na bibliografia anexa. Ele se refere a desenvolvimentos no mundo de fala inglesa, mas espero que seja de interesse mais amplo.

Em 1995 fiz, sem grande sucesso, uma tentativa de falar sobre o nascimento de Louise Brown com um conhecido, nos planaltos de Papua Nova Guiné. ${ }^{1}$ Foi interessante ver quais eram as preocupações de meu interlocutor com a Fertilização In Vitro (FIV). Ele não conseguia imaginar precisamente como desenvolver um filho no útero de uma mãe podia ocorrer sem relações sexuais entre os pais. Não havia uma noção de concepção, isto é, um único momento de procriação, e o enigma sobre as relações sexuais existia porque, ordinariamente, de seu ponto de vista, um feto demandaria diversos atos de intercurso para ser alimentado $e$ moldado. Seu veredicto era de que, por qualquer milagre que a criança tivesse nascido, essa criança não seria capaz de ela mesma ter filhos. Ela simplesmente não teria absorvido suficiente nutrição fertilizante do seu pai a partir de suas relações com a sua mãe, nem de sua mãe através da nutrição corporal. Desnecessário dizer que nem ele, nem qualquer outra pessoa, tinha um quadro da "natureza" a partir do qual julgar tais atos. E, tanto quanto posso lembrar, ele não foi minimamente tocado pela idéia de que o material fertilizante podia provir de pessoas que não os pais. Mas ele achava que qualquer doador, como o médico, cujo trabalho

1 Há uma breve menção em Strathern (1999:65-66). 
claramente o impressionava, deveria ser compensado. Essas pessoas compensam aqueles que contribuem para o crescimento de uma criança nutrindo-a, rotineiramente um parente do lado materno da criança.

$\mathrm{O}$ que teria impressionado o antropólogo social numa conversa similar no Reino Unido na época é exatamente quanto as pessoas investem na idéia abstrata de natureza, de fato, apelando para ela para separar práticas legítimas das ilegítimas ${ }^{2}$; perguntas surgem rapidamente, por exemplo, sobre até que ponto a natureza pode ser ajudada. A segunda observação que um antropólogo social poderia ter feito diz respeito ao peso que as pessoas atribuem à fonte precisa do material genético que forma uma criança e, como uma observação menor bem articulada, a contribuição a seu desenvolvimento embrionário. Para essas pessoas (no Reino Unido) há uma diferença de gênero entre o pai e a mãe, na medida em que a mãe é vista como a fonte primária de nutrição corporal (Não poderiam nem sonhar em pagar por isso). Essas pessoas estão também muito preocupadas sobre quem sabe e quem não sabe como alguém é concebido, e se o próprio bebê nasceu legitimamente ou não.

Não posso nesta apresentação abordar muitos dos temas que seria fascinante desenvolver. Manter-me-ei tão próxima quanto possível da nossa rubrica: o efeito do campo das Tecnologias de Reprodução Assistida (TRA) sobre a disciplina.

O texto (Edwards, Bavister e Steptoe, 1969:632-35) de que estamos falando teve certamente muitos efeitos. Para apresentar um muito simples: os debates que seguiram o nascimento de Louise Brown no Reino Unido com freqüência replicaram o modo como a inovação científica tornou possível o tratamento de FIV. A

${ }^{2}$ Ou pode ser utilizada como uma régua de cálculo, alguns procedimentos sendo considerados "mais" ou "menos" naturais que outros (Jeanette Edwards, comunicação pessoal). 
lógica do debate faz uma mímica da lógica de uma descoberta científica seguida por seu impacto. Assim, ao chegar a um encontro interdisciplinar (então chamado de multidisciplinar) poderíamos prever um formato regular: a ciência viria em primeiro lugar, depois as aplicações médicas/clínicas e, em geral no fim, as "implicações sociais".

A estrutura poderia ter sido a oposta: teríamos começado pelo tipo de sociedade que apoiava o trabalho científico, se era receptiva ou não a essas inovações, $e$ com as condições de desenvolvimento que permitiram que a ciência florescesse. Então surgiu um fenômeno comparável na antropologia social, apenas com a ciência no final. Refiro-me aqui a listas de leituras de conferências universitárias, particularmente leituras sobre sistemas de parentesco; as inovações possibilitadas pelas TRA seriam adicionadas no final a um corpo de obras já existentes. Podia ter sido o caminho oposto: poderíamos ter começado com a tecnologia médica e considerado a diferença que ela fez para a investigação antropológica - tanto a pré-existente quanto a nova.

Se menciono palestras de graduação é porque as inovações tiveram impacto não só sobre a pesquisa em antropologia social, mas também sobre o ensino. De fato, o impacto na pesquisa foi relativamente modesto, enquanto que a ascensão na sala de aula - do tópico de TRA e a pesquisa antropológica que se seguiu - foi quase universal entre os departamentos de antropologia, $e$ também na Europa e na América do Norte, e não só no Reino Unido. $\mathrm{O}$ fenômeno da TRA começou a ser incorporado ao ensino tão logo começou a pesquisa. Seria exagerado dizer que o tema estava à espera de algo assim, mas a noção e implicações da

\footnotetext{
3 Isso é de memória. Não quero exagerar a observação - certamente essa ordem nem sempre foi seguida em publicações. Assim, enquanto a coleção legal/filosófica/teológica de pesquisa com embriões de Dyson e Harris (1990) abre com um biólogo, a coleção histórica de Dunstan (1990) sobre o embrião humano se encerra com Peter Braude e Martin Johnson sobre a ciência médica contemporânea (citando o paper da Nature). A Ciência Social não figura em nenhuma delas.
} 
Tecnologia de Reprodução Assistida ${ }^{4}$ certamente caíram em terreno fértil. Ao falar sobre como o tópico entra na disciplina, é preciso também falar sobre as condições que fizeram a disciplina tão receptiva a ele. Voltarei brevemente ao ensino no fim; a maior parte do que segue considera a pesquisa.

Qual foi exatamente o tópico, e o que foi recebido? Em termos históricos, a antropologia social no Reino Unido tomou interesse, no que era então conhecido como NRT [New Reproductive Technologies, daqui para frente NTR Novas Tecnologias Reprodutivas], num ponto em que a ciência já vinha filtrada pela realização médica das possibilidades esboçadas naquele texto. De fato, o interesse na própria ciência permaneceu adormecido por um longo tempo. ${ }^{5}$ As questões abordavam o tema numa forma social já desenvolvida nos primeiros dias de exploração em medicina reprodutiva: o debate público. Tanto "público" quanto "debate" são sinais aqui, mas o que significam é o relato popular e generalizado das questões em torno da FIV e possibilidades afins, e ele ganhou ímpeto nos anos que se seguiram ao primeiro nascimento por FIV. Assim, a cronologia para a antropologia social é parecida com o que segue. ${ }^{6}$

Nos vinte anos entre a publicação do artigo na Nature em 1969 e a Lei HFEA de 1990 no Reino Unido, houve muito poucas respostas até o tempo do Relatório de Mary Warnock (1984, publicado em 1985). ${ }^{7}$ Assim, no Reino Unido, o interesse

${ }^{4}$ Embora eu não saiba das listas de leituras! Suspeito que seu interesse feneceu.

${ }^{5} \mathrm{E}$, de fato, depois de um alvoroço inicial de interesse em embriões e a regra dos 14 dias, os detalhes dos procedimentos científicos ficaram adormecidos até que os antropólogos começaram a se voltar para a pesquisa com células tronco $e$ da assim chamada clonagem (p.ex., Franklin, 2007).

${ }^{6}$ Um bom relato é encontrado em Bonaccorso, 2007:2-7.

7 Mais ou menos ao mesmo tempo que o Relatório Warnock, foram encomendados relatórios tanto no Canadá como na Austrália. Nos EUA, a Comissão Presidencial para o Estudo de Problemas Éticos na Medicina e na Pesquisa Biomédica e Comportamental deu início a um estudo específico sobre a terapia genética em 1982 (Grobstein, 1990). 
antropológico só veio à tona nos últimos cinco anos desse período. A isso se seguiu uma década (aproximadamente a década de 90) durante a qual a antropologia construiu todos os tipos de problemas disciplinares e obras a partir do crescente interesse nas questões levantadas pela NTR/TRA. A última década (a partir de 2000) pode ser caracterizada pela normalização disciplinar para o estudo que envolvesse FIV e tratamentos afins, enquanto ao mesmo tempo as fronteiras da exploração se moviam lateralmente, durante algum tempo para a genômica, e então para o uso de drogas farmacêuticas, experiências clínicas e pesquisa de células-tronco. Na verdade, estou um tanto surpreendida, olhando para isso, por quão escassa permaneceu a base da pesquisa em termos dos estudos primários sobre a TRA. Isso pode ser devido, em parte, ao fato de que o interesse que a TRA gerou foi muito além dos debates sobre o modo de procriação, isto é, seu efeito se ampliou para outras questões e outros tópicos de pesquisa; ao mesmo tempo, a nova genética, entre outras coisas, tinha se estabelecido como lugar substancial de estudo muito antes do final dos três períodos que considero. ${ }^{8}$

Mas qual foi o interesse que veio à tona primeiro? Interesse no quê?

\footnotetext{
8 Não posso trazer para este texto todas as referências que gostaria, e ofereço, em lugar disso, uma bibliografia anexa. Ela é organizada segundo esses três períodos. A bibliografia é seletiva, não exaustiva. Para os dois primeiros períodos, algumas obras relacionadas são também oferecidas para dar uma sensação do contexto em que os antropólogos poderiam estar escrevendo; no terceiro, é salientada uma categoria de obras relacionadas. Os itens dão pelo menos uma noção parcial do alcance interdisciplinar.
} 


\section{Tem a antropologia uma opinião? (1984 - 1989) $)^{9}$}

Se o efeito mais significativo do artigo na Nature foi a demonstração, em 1978, de que aquilo que viria a ser conhecido como FIV funcionava, abaixo disso havia a reação pública. Agora, reação pública não é definitivamente o mesmo que a receptividade social à qual me referi; essa receptividade social requer que conheçamos o estado da sociedade ou cultura que torna possíveis certas coisas, uma questão de contexto ou précondição e não de reação, e não necessariamente articulada na opinião das pessoas. Entretanto, o que viria a atrapalhar o engajamento antropológico era a novidade pronta em que as verdades sociais já pareciam ter sido destiladas: esse conceito de "opinião pública". ${ }^{10}$

Por definição, uma opinião vem depois do fato. Certamente, opiniões e atitudes aparecem historicamente depois da ciência que comentam. O problema foi que, com a conjunção do público com o social, de fora, a ciência social em geral e a antropologia social em particular, passaram a ser entendidas como se estudassem "o que as pessoas pensavam" sobre as NTRs. O contexto da conjunção, esse "de fora," era uma cultura política que viria a ficar obcecada com exercícios de consulta - em contraste com o próprio Relatório Warnock, que fora escrito nos antigos tempos dos comitês auto-suficientes de especialistas. Não surpreende que tenha parecido que a antropologia social lidasse com alguma espécie de reação depois do fato (Edwards, 2004; Bonaccorso, no prelo). Além disso, por mais significativo que fosse o papel que a opinião pública viria a ter na assunção das novas

9 Um problema óbvio em tal micro-contagem é que a data de publicação que tantas vezes tomamos como a marca de uma obra pode estar quatro ou cinco anos defasada em relação ao início da pesquisa que levou a ela. Assim, talvez essas datas devessem ter também um desvio padrão de, digamos, meia década para cada lado.

${ }^{10}$ Quando a pesquisa lidava com "opiniões," "crenças" e "atitudes" as pessoas as tomavam como o objeto da ciência social e, portanto, da antropologia. 
possibilidades, ela se tornou desinteressante a alguns olhos pelo fato de que as pessoas de qualquer maneira "sempre têm opiniões".

Compreender o "ponto de vista do nativo" tem sido uma doutrina fundante da antropologia social. Mas o importante é entender exatamente como o que as pessoas articulam surge de suas circunstâncias sociais/culturais - o ponto de vista não deve ser encolhido até a noção de uma opinião. No entanto, o modo pelo qual a FIV apareceu em público no Reino Unido, o fato social que atraiu a atenção antropológica foi que as pessoas estavam articulando opiniões. ${ }^{11}$ Assim, o que entrou na antropologia não foi a ciência, ou a medicina, mas um discurso sobre atitudes. Isso teve conseqüências sobre a rapidez com que a antropologia se interessou por esses procedimentos. Também teve conseqüências sobre a maneira como se deve interpretar a postura disciplinar da antropologia social. De fora, muitos supuseram que ela estava ali para acrescentar uma outra opinião, e a maioria dos antropólogos estaria pronta e disposta a oferecê-la. Para muitos dos de dentro, a antropologia, ao lado disso e de maneira própria, estava tomando a mudança cultural como sua problemática: a formação de um novo conhecimento e de novas relações, inclusive relações cambiantes de poder.

Todavia, nem o Reino Unido nem a antropologia estavam por conta própria. Nos primeiros anos, os antropólogos se encontraram forçosamente em contextos interdisciplinares, com sociólogos, clínicos e especialistas médicos. ${ }^{12} \mathrm{Um}$ painel no encontro da Associação Antropológica Norte-Americana em 1985 levou a uma coletânea de ensaios interdisciplinares sobre as

\footnotetext{
${ }^{11}$ Não penso que os antropólogos na época tenham feito sempre uma distinção suficientemente clara entre um interesse na opinião pública como artefato cultural, isto é, um objeto de conhecimento vernacular, e o interesse no papel que a FIV e afins tinham nas vidas das pessoas.

${ }^{12}$ Antropólogos continuaram publicando em coletâneas interdisciplinares através do Segundo período, de 1990 a 1999 (p.ex. Daniels e Haimes, 1998; Floyd e Dumit, 1998; McNeil, Varcoe e Yerley, 1990; Stacey, 1992; Ulanowski, 1995).
} 
dimensões sociais e éticas da reprodução humana (Whiteford $e$ Poland, 1989). ${ }^{13}$ As citações eram extraídas de juristas, de especialistas em ética e de uma gama de obras médicas sobre reprodução, mas não havia nada de antropologia. Eu não tive conhecimento do painel na época. Dois anos mais tarde, outro painel, desta vez de cientistas sociais, principalmente sociólogos, foi reunido nos encontros da Associação Sociológica Britânica (McNeil, Varcoe e Yearley, 1990), embora eu também não tenha sabido dele. Foi só quando um sociólogo da medicina naquele ano (1987) me perguntou se a antropologia tinha uma opinião sobre a doação de óvulos entre irmãs (ela não tinha!) que, por assim dizer, eu acordei. É claro que, nesse caso, o que me fora solicitado era um pouco mais que uma opinião - as perguntas eram: o que sabíamos? que trabalho tinha sido realizado? Para essas as respostas da antropologia do Reino Unido eram "muito pouco" e "nada". Então, acordei para o quê?

Acordei para o fato de que havia aqui pessoas de língua inglesa debatendo o que só podia ser descrito como parentesco. $\mathrm{O}$ parentesco já não podia mais ser um domínio que os antropólogos reservavam para si mesmos. O termo era tão prevalente naqueles dias que alguns podem se surpreender em saber que chegou a ser jargão (as pessoas de língua inglesa entre elas falavam principalmente em famílias e parentes e lares). Mas pronunciassem ou não a palavra, "parentesco" era definitivamente o fenômeno que se discutia: como se imagina que a procriação cria cadeias de conexões, conceitos e classificações sobre o modo como as pessoas se relacionam entre si. Embora eu deva acrescentar de uma vez que a questão não poderia ser posta desse modo hoje (Carsten, 2004; Bamford, 2007). De qualquer modo, parecia então que as novas possibilidades criavam novas cadeias em todas essas

\footnotetext{
${ }^{13}$ Embora eu reconheça a contribuição da antropologia dos EUA, um relato completo deveria tomar também a Europa, especialmente a França e a Espanha. $\mathrm{Na}$ Austrália (desde seus dias pioneiros de FIV) e no Canadá (com suas concisas consultas públicas), foram os sociólogos mais que os antropólogos que ocuparam um nicho crítico.
} 
direções, alongando a rede de procriação. Repentinamente, as pessoas de língua inglesa estavam discutindo o que constituía a paternidade e a maternidade, preocupando-se com quem era a mãe ou o pai "real", debatendo a relação entre natureza e criação, $e$, acima de tudo, talvez tornando familiar o que era algo como um segredo profissional entre os antropólogos, que as relações sociais $e$ as biológicas podiam ser separadas por oferecerem distintos modos de consideração. Não era só que isso criava um terreno familiar para o antropólogo. $\mathrm{O}$ que isso sinalizava era a oportunidade de pensar novamente sobre o parentesco euroamericano, $e$ as suposições sobre as quais ele se baseava. Não se tratava de uma visão estreita e de nenhuma maneira se restringia à consideração da família como tal: considerável parte da história e criatividade da antropologia social estava envolvida com distanciar-se dos supostos sobre relações mergulhadas no vernáculo inglês. Qualquer coisa que criasse uma alavanca sobre o vernáculo era excitante.

Uma oportunidade de examinar suposições foi o tema da reação antropológica imediata ao Relatório Warnock no Reino Unido (Rivière, 1985; ver também Cannell, 1990). De fato, Rivière expôs tudo que um antropólogo poderia desejar dizer sobre as hesitações e temores específicos que o público parecia proclamar e que era citado no relatório. Na escala maior dos diferentes sistemas de parentesco, ele perguntava qual era o motivo de tanto barulho (particularmente a propósito do parentesco social $e$ biológico). E conclui, "se víssemos nossos problemas numa perspectiva mais ampla, ...então as mães substitutas poderiam não parecer a ameaça à civilização em que algumas pessoas as tentam transformar" (Rivière, 1985:6). Ao mesmo tempo, reconhecendo a tenacidade das idéias locais sobre a paternidade e a maternidade naturais e sociais, ele imaginava que as pessoas no Reino Unido continuariam se sentindo desconfortáveis durante algum tempo.

Há duas considerações a fazer. Primeiro, quando a pergunta sobre a doação de óvulos entre irmãs me foi feita, era uma das muitas perguntas possiveis que circulavam na época: ela provinha 
de um grande conjunto de preocupações, já no âmago das coisas, como sabiam os sociólogos e filósofos, pois a FIV tinha feito surgir diversas possibilidades de arranjos sociais. Poderíamos falar de uma verdadeira explosão de questões, como se as preocupações éticas e sociais viessem à tona mais ou menos juntas e mais ou menos ao mesmo tempo! De fato, na época do Relatório Warnock, as conseqüências da FIV e procedimentos relacionados eram interpretados através de uma série delas: inseminação artificial, doação de gametas, substituição, pesquisa com embriões, diagnósticos pré-implantação. À parte o interesse na FIV, Rivière tinha comentários a oferecer sobre os quatro primeiros. Segundo, a perspectiva do parentesco dava um ponto de apoio numa das perguntas de fronteira que era feita. Com toda a novidade da tecnologia ou do procedimento clínico, eram novas ou velhas as formas sociais emergentes? E talvez o que podia parecer novo não fosse nem mesmo novo para "nós" (Stolcke, 1986). Essa questão, por sua vez, repunha uma disputa já assumida entre diversos comentaristas sobre quais eram as ainda chamadas de novas tecnologias reprodutivas, entre aqueles que não viam nada de novo e os que viam tudo como novo.

Mas voltemos ao ponto. Quando, eventualmente, o interesse antropológico foi galvanizado, o que o tornou receptivo? O que já estava em andamento?

\section{Preparando o campo (1990-1999)}

A pergunta sobre o que já estava em andamento pode ser respondida de duas maneiras, a primeira relativa à antropologia social como disciplina e a segunda a respeito do material sobre o qual os antropólogos podiam trabalhar.

No que diz respeito à disciplina, não é freqüente que se possa apontar para a obra de um único indivíduo. Mas, neste caso, o antropólogo norte-americano David Schneider construiu grande parte da receptividade da antropologia. Ele não se ocupava diretamente das TRA/NTR, mas encorajou pesquisadores 
mais jovens a pensar fora dos cânones, e especificamente encorajou uma pequena coorte de antropólogas feministas nos EUA. ${ }^{14}$ Mas sua influência foi muito mais ampla do que isso. Através de seus escritos sobre o parentesco norte-americano, ele mudou a direção dos estudos de parentesco, impacto que também foi sentido no Reino Unido. ${ }^{15} \mathrm{E}$, o que é particularmente importante para o tópico em exame, ele permitiu que a antropologia apreendesse (como objeto de conhecimento) o significado simbólico da biologia ou do pensamento biogenético na formação do parentesco euro-americano. Assim, a noção inglesa de paternidade/maternidade como o reconhecimento legal/social de uma relação biológica era um exemplo da "naturalização" de valores que permeiam o pensamento euroamericano. Isso finalmente pôs um paradeiro na antiga ingenuidade nos estudos de parentesco segundo a qual "os outros" tinham sistemas simbólicos e "nós" conhecíamos a biologia. Com o advento das TRA, a antropologia ganhou as ferramentas conceituais com que provocar os debates sobre quem é o pai/mãe "real," quem é o "artificial," e assim por diante.

$\mathrm{O}$ que estava em andamento na antropologia social, então, era o estudo do parentesco, central a tantos desenvolvimentos no tema de uma maneira que não valia para sua disciplina irmã, a sociologia. $\mathrm{O}$ que estava em andamento em termos mais gerais era a antropologia simbólica (e interpretativa), muito mais ampla que o parentesco, com seu investimento em discurso, representações, interpretações, narrativas. De qualquer forma, o

\footnotetext{
${ }^{14}$ Inclusive Ragoné e Weston, bem como o advogado-antropólogo Dolgin. [O interesse de Schneider em sistemas culturais, isto é, simbólicos, era pertinente aqui, especialmente sua análise do parentesco norte-americano, e sua teorização da pessoa. O papel fundador que ele deu à "lei" (código) é interessante à luz do grande papel que os juristas viriam a ter como comentaristas especializados em seu próprio sistema de parentesco].

${ }^{15}$ Embora eu lembre que, quando aderi às idéias de Schneider, primeiro num estudo de um vilarejo de Essex e depois numa exposição mais geral sobre o parentesco inglês, eu me senti bastante ousada!
} 
construcionismo social voava alto... e nele se encaixavam perfeitamente os argumentos sobre parentesco social e biológico. E quero fazer uma consideração sobre a especificidade desses nichos conceituais. Pois muitas das questões levantadas pelas TRA/NTR podiam ser enquadradas nas preocupações antropológicas existentes de maneira bem precisa. Um exemplo foi um renascimento do interesse no paradigma natureza-cultura. Os estudos antropológicos durante muito tempo tinham estabelecido um contraste entre o que era chamado de parentesco doméstico e o desenvolvimento de idéias e valores do parentesco em relação a questões sociais e político-econômicas "mais amplas." A redescoberta feminista do papel subordinado do parentesco doméstico por sua assimilação à natureza, por oposição à cultura, estava sob intenso debate. Se minha primeira reação fora de que aqui (no Reino Unido) repentinamente os ingleses falavam sobre o parentesco, a segunda reação foi de aqui os nativos ingleses estavam falando sobre natureza $e$ cultura!

Talvez esse "falar sobre" não impressione os não antropólogos como particularmente significativo, então vou expandí-lo. Não era simplesmente que as pessoas expressassem opiniões sobre tópicos sobre os quais os próprios antropólogos argumentavam, mas sim que tornavam explícitos seus valores $e$ idéias (cf. Strathern, 1992c). E, entre outras coisas, o que tornavam explícito era a percepção euro-americana da biologia como parte da ordem natural, um contexto seguro não só da procriação, mas da vida social. Poder-se-ia com justiça dizer que esse novo "explícito" vinha de uma poderosa mistura de inovação tecnológica e opinião pública (Franklin, comunicação pessoal). Em qualquer caso, o status garantido dos fatos biológicos era deslocado pela necessidade de conservar, auxiliar ou defender o funcionamento da "natureza." A sociedade tinha um novo projeto a seu alcance! Como não se interessar?

Uma das principais influências na receptividade da antropologia foi a reação feminista à idéia dos bebês de proveta (depois de 1978) e, mais particularmente no Reino Unido, aos 
debates estimulados pelo Relatório Warnock. De fato, comentaristas feministas foram rápidas, e a bibliografia de 1984-99 dá diversos exemplos de reflexão feminista. Digo reflexão conscientemente: alguns desses escritos figuram entre os mais perceptivos e interessantes daquela época. Para muitas, havia também uma agenda política (a organização internacional $e$ interdisciplinar ${ }^{16}$ Rede Feminista Internacional sobre as Novas Tecnologias Reprodutivas ${ }^{17}$, estabelecida em 1984). Ativistas feministas colocariam essa resposta num arcabouço histórico mais longo, datando de meados dos anos 1970, quando a crítica das intervenções reprodutivas ${ }^{18}$ decolou. Mas para os antropólogos sociais, esse momento em meados dos anos 1980 em que apareceram várias obras, foi um marco significativo: naquele então, a antropologia tinha assistido a uma década de escritos feministas dentro da própria disciplina. A antropologia feminista e seu primo próximo, o estudo das relações de gênero - tivera seu impacto na disciplina como um todo. ${ }^{19}$ Assim, quando finalmente

\footnotetext{
${ }^{16}$ Mas a filiação não era confinada à academia: essas ativistas vinham de meios muito diversos.
}

${ }^{17}$ FINNRET, que, em 1985, se tornou FINRRAGE, Feminist International Network of Resistance to Reproductive and Genetic Engineering. A rede inicialmente coordenava contados em 20 países no Primeiro e Terceiro Mundos. Ver Spallone e Steinberg, 1987.

${ }^{18}$ Os primeiros debates (eles mesmos com uma história prévia de preocupação com modos de dominação e de opressão) lidavam com controle da natalidade e aborto e a "apropriação" dos corpos das mulheres pela prática médica. Rose (1987:152) vê o nascimento de Louise Brown como um divisor de águas simbólico. Sua existência mudou as regras básicas: "o gato da FIV fugiu do saco, $e$ - seja o que for que a FIV faça - ela atende a necessidades reais de (algumas) mulheres reais." Uma coisa é argumentar teoricamente contra uma tecnologia previsível, outra, muito diferente, quando vidas de mulheres estão envolvidas com elas. Observo aqui que a perspectiva da engenharia genética estava também no ar naquela época, e é frequentemente considerada como parte do campo sob crítica.

${ }^{19}$ Foi durante o encontro decenal da American Sociological Association, em 1983, que Sir Edmund Leach foi ouvido observando que, de todas as seções, 
os antropólogos entraram na arena das TRA/NTR, já havia um corpo de literatura feminista crítica. Tipicamente, essa literatura ia além das questões imediatas da FIV, e diversas obras tinham sido produzidas, $e$ outras viriam a sê-lo, sobre a reprodução $e$ a maternidade em geral, algumas delas de alcance global. Havia outras ainda sobre tecnologias médicas relacionadas (tais como amniocentese) ou práticas (tais como inseminação artificial por doador fora da clínica). Muitas constam da bibliografia como modo de referir esse contexto. ${ }^{20}$

Poderia acrescentar que a ênfase sobre a TRA/NTR como ameaça, colocando problemas não previstos para os relacionamentos humanos, ou para a própria idéia do que era humano, era uma tendência bem mais leve de boa parte da primeira crítica antropológica. Tomando Rivière como lido, a atenção foi focada nas razões porque as pessoas aqui continuariam a se sentir desconfortáveis, e às vezes o antropólogo pode ter sentido que ele ou ela sabia mais do que eles por que se sentiam assim! As coisas mudaram desde então, mas podemos notar a problematização como uma entrada altamente produtiva num campo novo. E o que os antropólogos começaram a fazer?

Muitos dos estudos produzidos nesse período enfocaram o fenômeno da NTR/TRA da maneira como intervinha nas vidas das pessoas. Isso significava como os vários procedimentos eram entendidos, como as pessoas negociavam os novos relacionamentos sociais que estavam implicados - as fontes dos gametas doados, por exemplo, ou o papel do clínico em completar uma família, ou o diferente número de mães e pais que contribuem para um nascimento - e o efeito das promessas e da

aquela sobre questões feministas organizada por Shirley Ardener prometia ser a (intelectualmente) mais estimulante.

${ }^{20}$ Isso é tão indicativo quanto qualquer outra coisa. Outros corpos de literatura relevante incluem reflexões sobre "mulheres e tecnologia", muito antes que a noção de tecnologia reprodutiva decolasse. Concomitante ao interesse nas TRA/NTR, surgiu grande número de obras sobre "o corpo", interdisciplinares, mas particularmente vibrantes em sociologia. 
retórica que acompanhava os tratamentos. Isso envolvia entrevistas com pessoas que tinham passado por programas de fertilidade, e com aquelas para as quais a prática era agora parte de seu mundo social, independente de que eles mesmos a tenham usado ou não. Houve um ou dois estudos em clínicas, mas quanto aos outros era uma questão de perguntar que diferença a própria conceitualização de TRA/NTR, e as possibilidades que suas diversas manifestações abriam, fazia para o que as pessoas davam por assentado. ${ }^{21}$ Trabalho de campo detalhado que viria a resultar em monografias vinha sendo realizado, nenhum deles publicado, com exceção de duas obras pioneiras, Ragoné (1994) e Franklin (1997). ${ }^{22}$

Mas esses estudos não aconteciam num vazio textual. Ao contrário, se os antropólogos estavam interessados em pesquisa empírica era para estabelecer a investigação no campo ao lado da pletora de debates, opiniões, avaliações, estereótipos $e$ pronunciamentos reguladores. A explosão de questões se referia a que elas eram debatidas em público, no rádio e na televisão e na imprensa escrita. Isso era material no qual a antropologia se baseava para sua compreensão dos fenômenos, e foi também objeto de pesquisa. Faço aqui pouco mais do que listar os tipos de fontes.

Os meios de comunicação estavam obcecados na época com relatos de casos individuais que pudessem render "estórias" pessoais íntimas. Muitas relatavam inovações de pessoas que

${ }^{21}$ A questão sendo que no vernáculo certos processos "naturais", inclusive aqueles relativos à reprodução, eram tomados como a natureza inalterável contra a qual a cultura se exercia. A nova pergunta era precisamente o que estava sendo alterado.

${ }^{22}$ No entanto, esses pertenciam a uma "família" maior de monografias, derivando amplamente da tradição antropológica feminista nos EUA sobre tópicos nas fronteiras da TRA/NTR (p.ex., Weston [1991] sobre famílias criadas através de inseminação artificial; Rapp [1999] sobre o conhecimento genético no contexto de diagnósticos pré-natais), ou a partir do crescente interesse comparativo sobre infertilidade e maternidade (p.ex., Inghom, 1993). 
excediam de longe o tipo de soluções familiares nos quais os benefícios da TRA/NTR eram defendidos pela profissão médica. Assim, em 1991, participei de um simpósio na Faculdade de Medicina do Hospital de Londres sobre a controvérsia do assim chamado nascimento virgem, que se seguiu à descoberta de que algumas mulheres pretensamente procuravam a FIV a fim de procriar evitando inteiramente relações sexuais. ${ }^{23}$ As ações das pessoas e as escolhas que faziam também as levavam a disputas e aos tribunais (e daí aos meios de comunicação), que levavam o antropólogo a relatórios legais, ações legais e julgamentos. Aqui poríamos, por exemplo, contratos de substituição (ou de "mães de aluguel") - arranjos sociais que não têm nada a ver diretamente com a ciência ou com a medicina reprodutiva $e$ tudo a ver com as conseqüências para o parentesco. Finalmente, havia as regulamentações e suposições culturais que pareciam parte delas. Textos, como os debates parlamentares (Franklin, em Edwards et alii, 1993), estavam maduros para estudo, como também o estavam comentários sobre textos (cf. Morgan e Lee, 1991). Como a FIV se expandiu rapidamente para diferentes países, um dos interesses comparativos era o estudo do contraste entre a regulamentação fraca e forte das clínicas de fertilidade.

Além do "trabalho de campo" em clínicas, ou com doadores e receptoras no caso de doação de gametas, essas diferentes fontes de discurso ofereciam à investigação antropológica textos de todo tipo. Em si mesmos, eles pediam reflexão. Contudo, foi em parte isto que enviesou o estudo antropológico através do conceito importado de "opinião." (Uma vez que boa parte do material textual vinha formatada em termos da visão vernacular de opiniões e atitudes). À medida que o impacto "social" era visto pelos não antropólogos como derivado de mudanças que aconteciam em outro lugar (ver a introdução), os antropólogos

\footnotetext{
${ }^{23}$ Assim, a solução não pode ser vista como a assistência a uma parceira no ato de procriar. Ver Silman, 2003.
} 
achavam difícil defender o interesse que o "social" tinha para eles, e nem sempre o faziam bem. ${ }^{24}$

\section{Normalizando o campo (2000-2009)}

O interesse na TRA e suas repercussões fazem hoje parte da disciplina. Ele assume seu lugar ao lado de outras questões do momento, como o ambientalismo, direitos de propriedade intelectual ou a influência da mídia, que emanam de preocupações e formas sociais euro-americanas, mas são globalmente aplicáveis. A antropologia social acompanhou o internacionalismo dos primeiros escritos feministas, mas à sua maneira, através de seu método comparativo. Há agora um pequeno, mas respeitável, corpo de literatura sobre a TRA do modo como ela é praticada além do mundo de língua inglesa $e$ além da Europa. ${ }^{25}$

Sempre houve uma dimensão européia no trabalho que interessava aos antropólogos do Reino Unido, embora eu não possa entrar em detalhes sobre isso. Encorajadas por possibilidades de recursos europeus, muitas conferências reuniram novas constelações de especialistas e reuniões de colegas (p. ex., Brazier, Harris e Holm, 1998, iniciado por um jurista e especialistas em bioética). ${ }^{26} \mathrm{~A}$ diferença nos regimes regulatórios através da Europa

\footnotetext{
${ }^{24}$ Não me referi a ELSI [Implicações Éticas, Legais e Sociais] no contexto mais amplo dos estudos de ciência e sociedade, mas note-se que frequentemente surgia uma hierarquia dentro das ciências sociais entre as implicações consideradas éticas - legais - sociais, nessa ordem.

${ }^{25}$ Meus sinceros agradecimentos a Merve Demircioglu, da Universidade de Cambridge, que, em meio a seu próprio estudo de infertilidade e TRA na Turquia, compilou uma bibliografia sobre essas fontes.

${ }^{26}$ Iniciado por antropólogos, um estudo intercultural e etnográfico de sete países europeus organizado por Edwards focalizava-se não sobre a TRA como tal, sobre a qual ela trabalhara antes, mas sobre o entendimento público da genética. A coletânea editada (Edwards e Salazar, 2009) reúne TRA, adoção transnacional, paternidade/maternidade homossexual $e$ alimentos geneticamente modificados ao considerar questões de parentesco.
} 
levou à investigação (Bonaccorso, 2004a, 2009). De fato, o campo da TRA teve também uma pequena influência na expansão da antropologia na Grã Bretanha e na Europa.

$\mathrm{Se}$ a comparação entre regimes sociais ("comparação intercultural") era um modo pelo qual vinham à tona interesses disciplinares duradouros, outro era a monografia etnográfica. Esse é o período, no Reino Unido, onde vemos o surgimento de monografias plenas, derivadas de trabalho de campo, sejam concentradas em pesquisas em um só lugar ou deliberadamente em múltiplos lugares. Aqui no Reino Unido foram notáveis um estudo de campo que colocava as questões sobre a TRA no contexto social das vidas e preocupações das pessoas (Edwards, 2000) e um estudo focado em dois conjuntos de atores, doadores e recipientes em doação de óvulos (Konrad, 2005a). A genética provocou alguma pesquisa de laboratório, mas não em TRA. Esse trabalho antropológico era principalmente de pesquisa sobre as práticas clínicas e familiares de concepção assistida e das pessoas envolvidas nelas. Um dos resultados de tal exploração etnográfica detalhada foi descobrir modos até então inesperados pelos quais as pessoas interpretavam sua liberdade (ou falta de liberdade) de agir, e afirmavam sua própria atuação ou conhecimento em face de outros tipos de saber. As etnografias também atestam a maturidade da absorção dos estudos de TRA pela disciplina. Num campo maduro, estudos de um só local tornam-se fonte geral de insight analítico e de metáforas criativas.

Quero dizer com isso que questões ou imagens apresentadas pela TRA tornam-se recursos conceituais para entender outras coisas. Por exemplo, a doação de gametas se torna um modo interessante para pensar sobre doação de sangue (Copeman, no prelo), ou a divisão de atores da procriação vira um modo de pensar sobre a divisão dos cuidadores na adoção transnacional (Howell, 2006), ou um novo objeto de conhecimento pode ser criado, como no fenômeno da anonimidade e de "relações anônimas" (Konrad, 2005a). Os antropólogos, acostumados a encontrar situações nunca antes descritas, estão 
sempre procurando ampliar seu vocabulário descritivo e analítico, $e$ pode haver muito o que aprender, tratando em conjunto diferentes questões. A comparação ou analogia atua como um teste das reações e suposições das pessoas.

Mais radicalmente, contrastes com práticas de lugares muito diferentes podem render outro tipo de dividendo. Explorar a TRA em situações não européias (por exemplo, no Egito, Israel, Líbano, Botsuana, Sri Lanka) pode também se tornar um teste de pesquisa (como em Bamford, 2007). Isto é, estimula a pesquisa das suposições, valores e práticas no contexto doméstico, bem como no do estudo. Porém, talvez o ponto do exercício não seja o que mais pode ser aprendido sobre a TRA, mas o que o estudo desse tópico particular em outro lugar pode nos dizer sobre questões sociais ou culturais mais gerais - como o caráter da socialidade ou da personalidade ou da governança - tanto "lá" como "aqui". ${ }^{27}$ Mas muitas práticas podem atuar como testes. O que especificamente a TRA ajudou a criar?

Como intervenção "médica" que parece disponível para os inférteis enquanto pessoas privadas, quem quer que sejam, a TRA é extremamente acessível - quase ubíqua. Usuários ou não, todos podem dar uma olhada. Já sugeri que nos estudos antropológicos os efeitos da TRA são tanto uma questão das condições prévias que fizeram um tópico de interesse quanto de seu impacto subseqüente. Entretanto, quanto mais estudos são empreendidos em lugares específicos, mais se torna evidente que a infra-estrutura da TRA, em termos de competência técnica, tem um alcance global. O que então fica muito interessante é até que ponto outras idéias viajam com ela. Deixo de lado a possibilidade de exportação da ética e do direito. A área que provavelmente afeta mais as pessoas em seu caráter privado é o parentesco. Também seria interessante saber quão longe viajam as idéias euro-

${ }^{27}$ Isso, por sua vez, pode contribuir para entender o contexto em que floresce a TRA. 
americanas de parentesco. ${ }^{28}$ Pode-se suspeitar que um bom pedaço do pensamento euro-americano sobre o parentesco é contrabandeado sob o abrigo da "biologia" (Bamford, 2007).

Mas não se deve supor demais. Práticas clínicas podem parecer "interferir" em alguns componentes do processo de procriação enquanto deixam intactas outras ideologias locais (Edwards, comunicação pessoal). Como sabemos, uma articulação que a TRA explicitou - o que os euro-americanos viam antes como um nexo de eventos naturais - coito, concepção $e$ nascimento - foi fragorosamente desarticulado na prática. A desarticulação na prática também torna mais fácil a desarticulação no pensamento. Seguindo uma extensa crítica antropológica da noção de substância (Carsten, 2004), é possível descrever sem contradição, e volto aqui a Papua Nova Guiné (Bamford, 2007), um povo cujas práticas de procriação não dependem de nenhum desses componentes - coito, concepção e nascimento. ${ }^{29}$ Podemos aqui, com o olhar renovado, voltar-nos para a experiência euroamericana e considerar algumas das maneiras experimentais em que (por exemplo) casais homossexuais criam famílias (Bonaccorso, 2009).

A "biologia" teve um efeito colateral intrigante. Não há dúvida de que o interesse na TRA levou alguns antropólogos a um interesse em estudos sobre a ciência, interesse que não estivera na agenda anterior (exceto como protesto feminista "contra" a tecnologia). Neste terceiro período, a "ciência" entrou de maneira interdisciplinar, com a História da Ciência e Estudos sobre Ciência $e$ Tecnologia. As fronteiras da exploração já tinham se movido lateralmente, como notado de início, para a genômica, e depois para intervenções farmacêuticas, tentativas clínicas, pesquisa com células-tronco e clonagem (Franklin e Roberts, 2006; Franklin, 2007).

${ }^{28}$ Mencionado na pesquisa de Bonaccorso no Sul da Itália (2009).

${ }^{29} \mathrm{Em}$ seu relato sobre os Kamea de Papua Nova Guiné, Bamford (2007) descobre que eles acreditam que os laços criados através da maternidade e da paternidade se apóiam em princípios muito diferentes, como a experiência de partilhar um útero comum ou as relações que um homem estabelece com a terra. 
De fato, um interesse em diagnósticos genéticos, como às vezes parte do procedimento de FIV, mas também muito além, esteve intermitentemente entrelaçado com os debates sobre a TRA (Finkler, 2000; Konrad, 2005b). Assim o que foi trazido pela tecnologia voltou à tecnologia. Os anos 1990, que viram a antropologia explorar uma gama de questões relativas à reprodução pelo seu interesse social, também continham, em movimento paralelo, o retorno à ciência que viria a dominar a década 2000-2009. ${ }^{30}$

\section{Fim}

Para a antropologia, a pergunta não pode ser que diferença o artigo na Nature fez. Já estávamos muito avançados para isso. Mas podemos perguntar que diferença fez a TRA.

A antropologia social é uma disciplina baseada na universidade. A normalização da pesquisa em TRA é evidente nos programas de curso, e retorno brevemente às observações na introdução. $\mathrm{Na}$ interpenetração entre ensino e pesquisa, é o programa de curso que muitas vezes mantêm vivos velhos debates, $e$ isso certamente vale para o interesse duradouro no paradigma natureza-cultura. Nunca sabemos as ferramentas que servirão e o tema nunca teve medo de convocar teorias $e$ conceitualizações originalmente forjadas sob circunstâncias diferentes. É sua nova aplicação que revigora.

Agora as pessoas sabiam - por algum tempo, pelo menos o que fazer com o parentesco outra vez!. O que Peletz (1995) chamou de repatriação dos estudos de parentesco foi assumido com entusiasmo (p.ex., Bedford, 2001) ${ }^{31}$, a ponto de que Schneider pode ser posto a descansar (Carsten, 2004). Isso não é trivial para a

\footnotetext{
${ }^{30}$ Muitas antes rotuladas de antropólogas feministas passaram a se interessar por questões de tecnologia.

${ }^{31}$ Embora não se deva desconsiderar a obstinada adesão de uma coorte de eruditos a antigos temas de investigação como terminologias de parentesco (p.ex. Godelier, Trautman e Tjon Sie Fat, 1998).
} 
disciplina. No entanto, a disciplina teve dificuldade algumas vezes para convencer os não antropólogos de que o parentesco não é uma questão trivial. Embora pudessem fazer isso melhor naquelas sociedades onde as relações de parentesco eram uma força organizadora da vida política e econômica, eram sempre atrapalhados pelas suposições que cercavam a consideração euroamericana do parentesco como de alguma maneira uma questão das famílias e da vida doméstica que estava aquém do significado público. $\mathrm{Ou}$, onde fazia parte das preocupações públicas, vinha à tona como questões controversas de previdência, políticas familiares $e$ atendimento de saúde, questões que retornavam à circunscrição das famílias e domicílios. Certamente, essa visão comprimida do parentesco foi incansavelmente criticada do ponto de vista teórico, muitas e muitas vezes. ${ }^{32} \mathrm{O}$ que a TRA trouxe foi um conjunto de materiais e casos e imagens que ligavam o parentesco a um significante de extraordinária força lateral nessas décadas, a "tecnologia".

\section{Referências bibliográficas (do texto)}

Godelier, M; Trautman, T. e TJon Sie Fat, F. E. Transformations of Kinship. Washington, Smithsonian Institution Press, 1998.

EDWARDS, R.G.; BAviSTeR; B.D. e StePTOE, P. C. Early stages of Fertilization in vitro of Human Oocytes Matured in vitro. Nature 221, 1969.

SILMAN, R. (org.) Virgin Birth. Whitechapel. WFT press, 2003

STRATHERn, Marilyn. Property, Substance and Effect: Anthropological

Essays on Persons and Things. Londres, Athlone Press, 1999.

${ }^{32} \mathrm{E}$ é um ponto em que antropologia há muito se aliou às pesquisadoras feministas. 


\section{Bibliografia indicativa: Antropologia Social e TRA*}

\section{4 - 1989}

Antropologia e TRA no contexto de outras obras

\section{Relatos antropológicos da TRA}

MODELL, Judith. Last chance babies: interpretations of parenthood in an in vitro fertilization program. Medical Anthropology Quarterly 3, 1989, pp.124-38.

RIVIÈRE, Peter. Unscrambling Parenthood: The Warnock Report, Anthropology Today 4, 1985, pp.2-7.

STOLCKE, Verena. New reproductive technologies - same old fatherhood? Critique of Anthropology 6, 1986, pp.5-32.

WhITEFORD, Linda M. e POLAND, Marilyn L. (orgs.) New approaches to human reproduction: Social and ethical dimensions. Boulder, Westview Press, 1989 [Dos encontros da American Anthropological Association, 1985 / Society for Applied Anthropology, 1986].

WOLFRAM, S. Surrogacy in the United Kingdom. In: WHITEFORD, L.M. e POLAND, M.L. (orgs.) New approaches to human reproduction: Social and ethical dimensions. Boulder, Westview Press, 1989.

\section{Outras obras relacionadas -antropologia social}

COLlieR, Jane e YANAGISAKO, Sylvia. Gender and kinship: Towards a unified analysis. Stanford, Stanford University Press, 1987.

DELANEY, Carol. The meaning of paternity and the virgin birth debate. Man 21, 1986, pp.494-513.

GINSBURG, Faye. Contested lives: the abortion debate in an American community. Berkeley, University of California Press, 1989.

\footnotetext{
* A data da publicação não é a data da pesquisa ou conferência; em alguns casos essa informação é acrescentada. No caso de volumes editados, especialmente os interdisciplinares, pode haver uma ou duas contribuições antropológicas / um ou dois papers sobre TRA/NTR, entre outros, e eles são alocados segundo aonde parecem caber. Neste campo, com seu alcance interdisciplinar, autores individuais podem reconhecer mais de uma disciplina, ou podem ser tratados como antropólogos honorários.
} 
A Antropologia e o advento da Fertilização In Vitro no Reino Unido

Procreation stories: reproduction, nurturance, and procreation in life narratives of abortion activists. American Ethnologist 14, 1987, pp.623-36.

Martin, Emily. The woman in the body. A cultural analysis of reproduction. Boston, Beacon Press, 1987.

MODELL, Judith. In search: the purported biological basis of parenthood. American Ethnologist 13, 1986, pp.646-61.

RAPP, Rayna. Chromosomes and communication: the discourse of genetic counselling. In: WHITEFORD, L.M. e POLAND, M.L. (orgs.) New approaches to human reproduction: Social and ethical dimensions. Boulder, Westview Press, 1989.

. The power of "positive" diagnosis: medical and material discourse on amniocentesis. In: BERGIN, K. and CRAWLEY, Michaelson. (orgs.) Childbirth in America: Anthropological perspectives. South Hadley-MA, Bergin \& Garvey, 1988.

. Moral pioneers: women, men and fetuses on a frontier of reproductive technology. Women and Health 13, 1987, pp.101-16.

SCHNEIDER, Davis. A critique of the study of kinship. Ann Arbor, Michigan University Press, 1984 [cf. American kinship: A cultural account. Englewood Cliffs, Prentice Hall, 1968].

SEGALEN, Martine. Historical anthropology of the family. Cambridge, Cambridge University Press, 1986 [trads. J. C. Whitehouse e S. Matthews].

WOLFRAM, S. In-laws and outlaws: Kinship and marriage in England. Londres, Croom Helm, 1987.

YANAGISAKO, Sylvia. The elementary structure of reproduction in kinship and gender studies. Paper apresentado no encontro da American Anthropological Association, Washington, DC., 1985.

\section{Outras obras relacionadas a TRA - não antropologia}

ARDITTI, Rita; KLEIN, Duelli e MINDEN, Shelley. Tube women: What future for motherhood?. Londres, Pandora Press, 1984.

CORREA, Gena. The mother-machine: Reproductive technologies from artificial insemination to artificial wombs. Nova York, Harper and Row, 1985. 
CROWE, Christine. "Women want it", in vitro fertilisation and women's motivations for participation. Women's Studies International Forum 8, 1985, pp.547-52.

FRANKLIN, Sarah e MCNEIL, Maureen. Reproductive futures: recent feminist debate of new reproductive technologies. Feminist Studies 14, 1988, pp.545-74.

GlOVER, Jonathan et alii. Fertility and the family: The Glover Report on the Reproductive Technologies to the European Commission. Londres, Fourth Estate, 1989.

KLEIN, Renate. Infertility: Women speak out about their experiences of reproductive medicine. Londres, Pandora Press, 1989.

MCWHINNIE, A. M. AID and infertility. Adoption and fostering 10, 1986, pp.16-18.

MoRGAN, Derek. Surrogacy: an introductory essay. In: LEE, R. and MORGAN, D. (orgs.) Birthrights: law and ethics at the beginning of life. Londres, Routledge, 1989.

NELKIN, Dorothy e TANCREDI, Laurence. Dangerous diagnostics: the social power of biological information. Nova York, Basic Books, 1989.

NELSON, Hilde L. e NELSON, James L. Cutting motherhood in two: some suspicions concerning surrogacy. Hypatia 4, 1989, pp.85-94.

PRICE, Frances. Establishing guidelines: regulation and the clinical management of infertility. In: LEE, R. e MORGAN, D. (orgs.) Birthrights: Law and Ethics at the Beginnings of Life. Londres, Routledge, 1989.

OAKLEY, Ann. From walking wombs to test-tube babies. In: Stanworth, Michelle. (org.) Reproductive Technologies: Gender, Motherhood and Medicine. Oxford, Polity Press, 1987.

ROSE, Hilary. Victorian values in a test-tube: the politics of reproductive science and technology. In: STANWORTH, Michelle. (org.) Reproductive Technologies: Gender, Motherhood and Medicine. Oxford, Polity Press, 1987.

SNOWden, R. e SnOWDEn, E. The Gift of a Child. Londres, Geo Allen \& Unwin, 1984.

e MitCHELL, G. D. The artificial family: a consideration of artificial insemination by donor. Londres, Unwin, 1981.

SPALlONE, Patricia. Beyond conception. Londres, Macmillan, 1989. 
e STEINBERG, Deborah L. (orgs.) Made to order: The myth of reproductive and genetic success. Oxford, Pergamon Press, 1987 [Da Women's Emergency Conference on the New Reproductive Technologies, 1985.]

STANWORTH, Michelle. (org.) Reproductive Technologies: Gender, Motherhood and Medicine. Oxford, Polity Press, 1987.

WARNOCK, M. A Question of Life: the Warnock Report on Human Fertilisation and Embryology. Oxford, Basil Blackwell, 1985.

\section{0 - 1999}

Antropologia e TRA se tornam uma linha de pesquisa (mais obras relacionadas selecionadas de outras disciplinas)

\section{Relatos antropológicos de TRA}

CANNELL, Fenella. Concepts of parenthood: the Warnock Report, the Gillick debate, and modern myths. American Ethnologist 17, 1990, pp.667-86.

DolgIN, Janet L. [Advogada e Antropóloga] Defining the Family: Law, Technology and Reproduction in an Uneasy age. Nova York, New York University Press, 1997.

. The "intent" of reproduction: reproductive technology and the parent-child bond. Univ. Connecticut Law Review 26, 1994, pp.1261-1314.

. Status and contract in feminist legal theory of the family: a reply to Bartlett. Women's Rights Law Reporter 12, 1990a, pp.103113.

Status and contract in surrogate motherhood: an illumination of the surrogacy debate. Buffalo Law Review 38, 1990b, pp.515-550.

EDWARDS, J. et alii. Technologies of Procreation: Kinship in the Age of Assisted Conception. Manchester, Manchester University Press, 1993 [Outros autores: Edwards, Franklin, Hirsch, Price, Strathern]; $2^{\mathrm{a}}$ edição, Londres, Routledge, 1999 [Pesquisa realizada no Reino Unido 1990-1991].

EDWARDS, J. Why Dolly Matters: Kinship, Culture and Cloning. Ethnos 64(3), 1999, pp.301-24. 
. Donor Insemination and "Public Opinion". In: Daniels, K. e Haimes, E. (orgs.) Donor Insemination International Social Science Perspectives. Cambridge, Cambridge University Press, 1998.

Explicit connections: ethnographic enquiry in north-west England. In: Edwards, J. et alii. Technologies of Procreation: Kinship in the Age of Assisted Conception. Manchester, Manchester University Press, 1993.

FoX, Robin. Reproduction and succession: Studies in anthropology, law, and society. New Brunswick, Transaction Publishers, 1993.

FRANKLIN, Sarah [Antropóloga e Socióloga]. The embryo research debate: Science and the politics of reproduction. Public Understanding of Science 7(3), 1998, pp.255-56.

. Embodied progress: a cultural account of assisted conception. Londres, Routledge, 1997 [Pesquisa realizada no Reino Unido 198792].

. Postmodern procreation: representing reproductive practice. Science as Culture 17, 1993, pp.522-61.

. Fetal fascinations: the construction of fetal personhood and the Alton debate. In: Franklin, S.; Lury, C. e Stacey, J. (orgs.) OffCentre: Feminism and Cultural Studies. Londres, Unwin-Hyman, 1991.

. Deconstructing "desperateness": the social construction of infertility in popular representations of new reproductive technologies. In: McNeil, M. et alii. (orgs.) The New Reproductive Technologies. Londres, Macmillan, 1990.

e Ragone, Helen. (orgs.) Reproducing reproduction: kinship, power and technological innovation. Philadelphia, University of Pennsylvania Press, 1998.

HAYDEN, Corinne P. Gender, genetics, and generation: reformulating biology in lesbian kinship. Cultural Anthropology 10, 1995, pp.41-63.

HIRSCH, E. Negotiated limits: interviews in south-east England. In: Edwards, J. et alii. Technologies of Procreation: Kinship in the Age of Assisted Conception. Manchester, Manchester University Press, 1993.

JAMES, Wendy. Placing the unborn: On the social construction of new life. Conferência Memorial Kaberry, University of Oxford, 1997. 
KONRAD, Monica. Ova donation and symbols of substance: some variations on the theme of sex, gender and the partible body. Man (NS) 4, 1998, pp.643-67.

RAGONÉ, Helena. Surrogate motherhood: Conception in the heart. Boulder, Westview Press, 1994 [Pesquisa realizada nos EUA 198890].

SHORE, Cris. Virgin birth and sterile debates. Current Anthropology 33, 1992, pp.295-314.

STRATHERN, M. Bisogno di padri, bisogno di madri. Le "madri vergini" in Inghilterra. In: Fiume, G. (org.) Madri: storia di un ruolo sociale. Veneza, Marsilio Editori, 1995.

. Displacing knowledge: technology and the consequences for kinship. In: Robinson, Ian. (org.) The social consequences of life and death under high technology medicine. Manchester, Manchester University Press, 1994.

. The meaning of assisted kinship. In: Stacey, M. (org.) Changing human reproduction: Social science perspectives. Londres, Sage, 1992a.

. Reproducing the future: Essays on anthropology, kinship and the new reproductive technologies. Manchester, Manchester University Press, $1992 b$.

. Disparities of embodiment: gender models in the context of the new reproductive technologies. Cambridge Anthropology 15, 1991, pp.25-43 [pub 1992].

. Finding out what the people would choose: a comment on the gathering of opinion. Relatório do Projeto de Pesquisa EC, Reproductive values: The individual and society, org. M. Brazier. Manchester, Centre for Social Ethics \& Policy [não publicado].

Antropologia, fora da Europa e dos EUA, sobre a infertilidade e náo sobre a TRA como tal (bibliografia compilada por Merve Demircioglu)

BELLER-HANN, I. Women, work and procreation beliefs in two Muslim communities. In: LoIZOS, P. and HEADY, P. (orgs.) Conceiving Persons: Ethnographies of Procreation, Fertility and Growth. Londres/New Brunswick, The Athlone Press, 1999, pp.177-199. 
Feldman-SaVelsberg, P. Plundered Kitchens, Empty Wombs: Threatened Reproduction and Identity in the Cameroon Grassfields. Ann Arbor, the University of Michigan Press, 1999.

INHORN, Marcia C. Infertility and patriarchy: The cultural politics of gender and family life in Egypt. Philadelphia, University of Pennsylvania Press, 1996.

medical traditions. Philadelphia, University of Pennsylvania Press, 1994.

KIELMAN, K. Barren ground: contesting identities of infertile women in Pemba, Tanzania. In: Lock, M. e Kaufert, P. A. (orgs.) Pragmatic Women and Body Politics. Cambridge, Cambridge University Press, 1998, pp.127-163.

NEFF, D. L. The social construction of infertility: the case of the matrilineal Nayars in South India. Social Science and Medicine 39(4), 1994, pp.475-85.

\section{Outras obras relacionadas - antropologia social}

ABRAHAMS, Ray. Plus ça change, plus c'est la même chose? [Organ donation and kinship]. Australian Journal of Anthropology, número especial - On the Generation and Maintenance of Person -W. Shapiro (org.), 1990.

BATTAGLIA, Debbora. Fear of selfing in the American cultural imaginary; or "You are never alone with a clone". American Anthropologist 97(4), 1995, pp.672-78.

BESTARD-CAMPS, Joan. What's in a relative? Household and family in Formentera. Oxford, Berg, 1991 [Trad. da edição de 1986].

BOUQUET, Mary. Reclaiming English kinship: Portuguese refractions of British kinship theory. Manchester, Manchester University Press, 1993.

DESCOLA, Philippe. Societies of nature and the nature of society. In: KupER, A. (org.) Conceptualising society. Londres, Routledge, 1992.

GINSBURG, Faye D. e RAPP, Rayna. The politics of reproduction. Annual Review of Anthropology 20, 1991, pp.311-43.

. (orgs.) Conceiving the new world order: the global politics of reproduction. Berkeley, University of California Press, 1995. 
Heritier, F. Les Deux sœurs et leur mère. Paris, Odile Jacob, 1994.

$\mathrm{HIRSCH}$, Eric. The long term and the short term of domestic consumption: an ethnographic case study. In: SILVERSTONE, R. e HIRSCH, E. (orgs.) Consuming technologies: media and information in domestic spaces. Londres, Routledge, 1992.

Holy, Ladislav. Anthropological perspectives on kinship. Londres, Pluto Press, 1996.

LAYNE, Linda. (ed.) Transformative motherhood: On giving and getting in a consumer culture. Nova York, New York University Press, 1999.

MARTIN, Emily. The egg and the sperm: how science has constructed a romance based on stereotypical male-female roles. Signs 16, 1991, pp.485-501.

PARKIN, R. Kinship: an introduction to basic concepts. Oxford, Blackwell, 1997.

PELETZ, M. Kinship studies in late twentieth century anthropology. Annual Review of Anthropology 24, 1995, pp.343-72.

RAPP, Rayna. Testing Women, Testing the Fetus: the Social Impact of Amniocentesis in America. Nova York, Routledge, 1999 [Diagnóstico genético pré-natal, pesquisa realizada nos EUA a partir dos anos 1980].

StONE, Linda. Kinship and gender: an introduction. Boulder, Westview Press, 1997.

STRATHERN, M. After nature: English kinship in the late twentieth century. Cambridge, Cambridge University Press, 1992c.

WeStON, K. Families we choose: Lesbian, gays, kinship. Nova York, Columbia University Press, 1991 [Pesquisa realizada nos EUA 198586].

\section{Outras obras sobre TRA e relacionadas - não antropologia}

BIRKE, Linda; Himmelweit, Susan and Vines, Gail. Tomorrow's child: Reproductive technologies in the 90s. Londres, Virago Press, 1990.

BROMHAM, David R.; DALTON, Maureen E. e JACKSON, Jennifer C. (orgs.) Philosophical ethics in reproductive medicine. Manchester, Manchester University Press, 1990 [Primeira conferência internacional sobre ética filosófica e medicina reprodutiva, 1988]. 
BRITISH MEDICAL ASSOCIATION REPORT. Changing conceptions of motherhood: The practice of surrogacy in Britain. Londres, BMA, 1996.

CHADWICK, R. Moral reasoning in family law: a response to Katherine O'Donovan. In: MORGAN, D. e Douglas, G. (orgs.) Constituting families: A study in governance. Stuttgart, Steiner, 1994.

ClothiER, C. Report of the Committee on the Ethics of Gene Therapy. Londres, H.M.S.O, 1992.

CUSSINS, Charis. Producing reproduction: techniques of normalization and naturalization in infertility clinics. In: Franklin, Sarah e Ragone, Helen. (orgs.) Reproducing reproduction: kinship, power and technological innovation. Philadelphia, University of Pennsylvania Press, 1998.

. Ontological choreography: agency through objectification in infertility clinics. Social Studies of Science 26, 1996, pp.575-610.

. Les cycles de la conception: les techniques de normalisation dans un centre de traitement de la stérilité. Techniques \& culture 2526, 1995, pp.307-38.

DANIELS, Ken e HAIMES, Erica. Donor insemination: International social science perspectives. Cambridge, Cambridge University Press, 1998.

DAVIS-FloyD, R. e DuMIT, J. (orgs.) Cyborg babies: From techno-sex to techno-tots. Nova York, Routledge, 1998.

DREYFus, R. C. e NelKIN, D. The jurisprudence of genetics. Vanderbilt Law Review 45, 1992, pp.313-348.

DUDEN, Barbara. Disembodying women: Perspectives on pregnancy and the unborn. Cambridge Mass., Harvard University Press, 1993 [trad. L Hoinacki].

DYSON, Anthony. At Heaven's Command? The Churches, Theology and Experiments on Embryos. In: DYSON, A. e HARRIS, J. (orgs.) Experiments on embryos. Londres, Routledge, 1990.

e HARRIS, John. (orgs.) Experiments on embryos. Londres, Routledge, 1990.

EEKELAAR, John e SARCEVIC, Peter. Parenthood in modern society: legal and social issues for the twenty-first century [International Society of Family Law]. Dordrecht, Martinus Nijhoff Publishers, 1993. 
A Antropologia e o advento da Fertilização In Vitro no Reino Unido

GROBSTEIN, Clifford. Genetic manipulation and experimentation. In: BROMHAM, David R.; Dalton, Maureen E. e JACKSON, Jennifer C. (orgs.) Philosophical Ethics in Reproductive Medicine. Manchester, Manchester University Press, 1990.

KANDEL, Randy Frances. Which came first: the mother or the egg? A kinship solution to gestational surrogacy. Rutgers Law Review 47, 1994, pp.165-239.

GUNNING, Jennifer e ENGLISH, Veronica. Human in vitro fertilization: A case study in the regulation of medical innovation. Dartmouth, Aldershot, 1993.

HAIMES, Erica. Issues of gender in gamete donation. Social Science and Medicine 36, 1993, pp.85-93.

. Gamete donation and the social management of genetic origins. In: STACEY, M. (org.) Changing Human Reproduction: Social Science perspectives. Londres, Sage, 1992.

. Recreating family? Policy considerations relating to the "new" reproductive technologies. In: MCNEIL, M. et alii. (orgs.) The new reproductive technologies. Londres, Macmillan, 1990.

HARAWAY, Donna. Simians, cyborgs, and women: The reinvention of nature. Nova York, Routledge, 1991.

HARRIS, John. Wonder woman and superman: The ethics of human biotechnology. Oxford, Oxford University Press, 1992.

e HOLM, Soren. (orgs.) The future of human reproduction. Oxford, Clarendon Press, 1998.

HARTOUNI, Valerie. Cultural conceptions: On reproductive technologies and the re-making of life. Minneapolis, University of Minnesota Press, 1997.

Containing women: Reproductive discourse in the 1980s. In: PENLEY, C. e ROsS, A. (orgs.) Technoculture. Minneapolis, University of Minnesota Press, 1991.

HuLL, Richard T. Ethical issues in the new reproductive technologies. Belmont CA, Wadsworth Publishing Co., 1990.

LAMB, David. Organ transplants and ethics. Londres, Routledge, 1990.

MCNeIL, Maureen; VARCOE, Ian e YeARLEy, Steven. (orgs.) The New Reproductive Technologies. Londres, Macmillan, 1990. 
MIRINGOFF, Marque-Luisa. The social costs of genetic welfare. New Brunswick, Rutgers University Press, 1991.

MoRGAN, Derek. A surrogacy issue: Who is the other mother?. Int. Journal of Law and Family 8, 1994, pp.386-412.

e LEE, Robert G. Human Fertilisation and Embryology Act 1990: Abortion and embryo research, the new law. Londres, Blackstone Press Ltd., 1991.

e DOUGLAS, G. (orgs.) Constituting Families: a study in governance. Stuttgart, Steiner, 1994.

MULKAY, Michael. The embryo research debate: Science and the politics of reproduction. Cambridge, Cambridge University Press, 1997.

MunÁRRIZ, Luis Álvarez e MUNOZ, Joaquín Guerrero. (orgs.) Biotecnología y familia: Factores socioculturales y éticos. Diego Marin Librero-Editor, 1999.

NELKIN, Dorothy. The social power of genetic information. In: KEVLES, D. K. e HoOD, L. (orgs.) The code of codes: scientific and social issues in the human genome project. Cambridge, Mass., Harvard University Press, 1992.

NIELSON, L. The right to a child versus the rights of a child. In: EEKELAAR, J. e SARCEVIC, P. Parenthood in modern society: Legal and social issues for the twenty-first century. Dordrecht, Martinus Nijhoff, 1993.

NOVAES, Simone. Les passeurs de gametes. Collection Ethiques et Techniques, Nancy, Presses Universitaires de Nancy, 1994.

e SALEM, Tania. Embedding the embryo. Presented to $2^{\text {nd }}$ plenary conference. EC Research Project Fertility, infertility and the human embryo, Barcelona, 1994.

- Giving, receiving, repaying: gamete donors and donor policies in reproductive medicine. Journal of Technology Assessment in Health Care 5, 1989, pp.639-57.

NufFIELD COUNCIL ON BiOETHICS. Human tissue: Ethical and legal issues. Londres, 1995.

. Genetic Screening: Ethical issues. Londres, 1993.

O'DONOVAN, K. Love's law: moral reasoning in the family. In: MORGAN, D. e Douglas, G. (orgs.) Constituting Families: a study in governance. Stuttgart, Steiner, 1994. 
A Antropologia e o advento da Fertilização In Vitro no Reino Unido

PRICE, Frances V. Beyond expectation: clinical practice and clinical concern. In: EDWARDS, J. et alii. Technologies of procreation: Kinship in the age of assisted conception. Manchester, Manchester University Press, 1993.

. The management of uncertainty in obstetric practice: Ultrasonography, in vitro fertilisation and embryo transfer. In: MCNeIL, M. et alii. (orgs.) The New Reproductive Technologies. Londres, Macmillan, 1990.

ROBERTSON, John A. Children of choice. Freedom and the new reproductive technologies. Princeton, Princeton University Press, 1994.

SEAL, Vivien. Whose choice? Working class women and the control of fertility. Londres, Fortress Books, 1990.

SERour, G. I.; El GHAR, M. e MANSOUR, T. In vitro fertilization and embryo transfer: Ethical aspects in techniques in the Muslim world. Population Sciences, 1990, pp.9-45.

Sex Selection: Public Consultation Document. Londres, Human Fertilisation and Embryology Authority, January 1993.

SPALlONE, Patricia. Generation games: Genetic engineering and the future of our lives. Londres, The Women's Press, 1992.

SQUIER, Susan M. Babies in bottles: Twentieth-Cenury visions of reproductive technology. Nova York, Rutgers University Press, 1994.

STACEY, Margaret. (org.) Changing human reproduction: a social science perspective. Londres, Sage, 1992.

STEINBERG, Deborah L. Bodies in glass: Genetics, eugenics, embryo ethics. Manchester, Manchester University Press, 1997.

UlANOWSKI, Carole (org.) The family in the age of biotechnology. Aldershot, Avebury, 1995.

\section{0 - 2009 Antropologia e TRA em perspective comparada}

\section{Relatos antropológicos de TRA}

BAMFORD, Sandra. Biology unmoored: Melanesian reflections on life and biotechnology. Berkeley, University of California Press, 2007. 
BEDFORD, Susan. A remembrance of kinship studies past: a call for their rebirth. History and Anthropology 12, 2001, pp.315-41 [Encontros canadenses de sociologia e antropologia, 1996.]

BECKER, Gay. The elusive embryo: How women and men approach new reproductive technologies. Berkeley, University of California Press, 2000.

BONACCORSO, Monica. Conceiving kinship: Assisted conception, procreation and family in Southern Europe. Oxford, Berghahn Books, 2009.

. Gamete donation: Strategies in (private) clinics of assisted conception. In: UNNITHAN, M. Reproductive change, medicine and the state: Ethnographic explorations of agency in childbearing. Oxford, Berghahn Books, 2004a, pp.82-102.

. Making connections: Family and relatedness in clinics of assisted conception in Italy. Journal of Modern Italy 9(1), 2004b, pp.59-68.

. Gamete donation in private clinics of assisted conception. Fast Facts-Gynaecology Highlights 2000-01, 2001, pp.59-67.

. The trivialisation of Social Anthropology: An ethnographic account. In: COLEMAN, S. e COLLINS, P. (orgs.) Dislocating anthropology? Bases of longing and belonging in the analysis of contemporary societies. Cambridge, Cambridge Scholars Press [in press].

Dolgin, Janet. Choice, tradition, and the new genetics: The fragmentation of the ideology of the family. Law Rev. 32, 2000, pp.523-66 [Doação de óvulos].

EDWARDS, Jeanette. Skipping a generation: Genealogy and assisted conception. In: BAMFORD, Sandra e LEACH, James. (orgs.) Kinship and beyond: The genealogical model reconsidered. Oxford, Berghahn Books, 2009.

. "Creativity" in English Baptist understandings of assisted and assisting conception. In: HAllam, E. e INGOLD, T. (orgs.) Creativity and Cultural Improvisation. Oxford, Berg, 2007.

. "Make-up": Personhood through the Lens of Biotechnology. Ethnos 70(3), 2005, pp.413-31. 
. "Public understanding of science": citizenship, deficit and democracy. In: RAPPORT, N. (org.) "Popper Revisited", edição especial, Anthropological Journal on European Cultures 13, 2004a, pp.51-68.

. Incorporating Incest: Gamete, Body and Relation in Assisted Conception. Journal of the Royal Anthropological Institute (N.S) 10, 2004b, pp.755-74.

Born and bred: Idioms of kinship and new reproductive technologies in England. Oxford, Oxford University Press, 2000 [Pesquisa no Reino Unido, 1987-90].

e SALAZAR, Carles. (eds.) European kinship in the age of biotechnology. Oxford/Nova York, Berghahn Books, 2009.

FINKLER, Kaja. Experiencing the new genetics: Family and kinship on the medical frontier. Philadelphia, University of Pennsylvania Press, 2000.

FRANKLIN, Sarah. Dolly mixtures: The remaking of genealogy. Durham, Duke University Press, 2007.

e LOCK, Margaret. (orgs.) Remaking life and death: Toward an Anthropology of the Biosciences. Santa Fe, School of American Research Press, 2001.

e MCKINNON, Susan. (orgs.) Relative values: reconfiguring kinship studies. Durham, Duke University Press, 2001 [Simpósio Wenner-Gren 1998].

HARRINGTON, Jennifer; Becker, Gay e Nachtigall, Robert. Nonreproductive technologies: Remediating kin structure with donor gametes. Science, Technology and Human Values 33, 2008, pp.393418 [Paper Interdisciplinar].

HAUSER-SCHÄUBLIN, Brigitta et alii. Der Geteilte Leib: Die kulturelle Dimension von Organ-transplantation und Reproduktionsmedizin in Deutschland. Frankfurt, Campus Verlag, 2001.

KONRAD, Monica. Nameless relations: Anonymity, Melanesia and reproductive gift exchange between British ova donors and recipients. Oxford, Berghahn Books, 2005a.

MELHUUS, Marit. "Better safe than sorry". Legislating assisted conception in Norway. In: KROHN-HANSEN, Christian e NUSTAD, Knut. (orgs.) State formation: Anthropological perspectives. Londres, Pluto, 2005. 
e HOWELL, Signe. Adoption and assisted conception: One universe of unnatural procreation. An examination of Norwegian legislation. In: EDWARDS, J. e SALAZAR, C. (orgs.) European Kinship in the Age of Biotechnology. Oxford, Berghahn Books, 2009.

OrOBitg, G. e SALAZAR, C. The Gift of Motherhood: Egg Donation in a Barcelona Infertility Clinic. Ethnos 70(1), 2005, pp.31-52.

RAGONÉ, Heléna. Of likeness and difference: How race is being transfigured by gestational surrogacy. In: RAGONÉ, H. e WINDDANCE, Twine F. (orgs.) Ideologies and technologies of motherhood: Race, class, sexuality, nationalism. Nova York, Routledge, 2000.

STRATHERN, Marilyn. Kinship, law and the unexpected: Relatives are always a surprise. Cambridge, Cambridge University Press, 2005.

. Still giving nature a helping hand? Surrogacy: a debate about technology and society. J. Molecular Biology 319, 2002, pp.985-93.

THOMPSON, Charis Cussins [STS] Making parents: The ontological choreography of reproductive technologies. Cambridge MA, MIT Press, 2005.

\section{Antropologia sobre TRA, fora da Europa e dos EUA (bibliografia compilada por Merve Demircioglu)}

ABBASI-SHAVAZI, M. et alii. The "Iranian ART Revolution"? Infertility, assisted reproductive technology, and third party donation in the Islamic Republic of Iran. J. of Middle East Women's Stud, vol. 4, 2008, pp.1-28.

BHARADWAJ, Aditya. Biosociality and biocrossings: Encounters with assisted conception and embryonic stem cells in India. In: GIBBON, S. e NovAS, C. (orgs.) Biosocialities, Genetics and the Social Sciences: Making Babies and Identities. Nova York, Routledge, 2008, pp.98116.

- Sacred modernity: religion, infertility, and technoscientific conception around the globe. Culture, Medicine and Psychiatry 30, 2006a, pp.423-425.

. Sacred conceptions: Clinical theodicies, uncertain science, and technologies of procreation in India. Culture, Medicine and Psychiatry 30, 2006b, pp.451-465. 
Why adoption is not an option in India: The visibility of infertility, the secrecy of donor insemination, and other cultural complexities. Social Science and Medicine 56, 2003, pp.1867-1880.

Conception politics: medical egos, media spotlights, and the contest over test -tube firsts in India. In: Inhorn, M. C. e Van Balen, F. (orgs.) Infertility around the globe. California, University of California Press, 2002, pp.315-333.

. How some Indian baby makers are made: Media narratives and assisted conception in India. Anthropology and Medicine 7, 2000, pp.63-78.

Birenbaum-Carmeli, D. e Carmeli, Y. S. (orgs.) Kin, Gene, Community: Reproductive Technology among Jewish Israelis. Nova York, Berghahn, 2009 [no prelo].

. e INHORN, M. (orgs.) Assisting Reproduction, Testing Genes: Global Encounters with New Biotechnologies. Oxford, Berghahn, 2009 [no prelo].

CLARKE, Morgan. Islam and new kinship: Reproductive technology, anthropology and the shari'ah in Lebanon. Nova York, Berghahn, 2009.

New kinship, Islam and the liberal tradition: Sexual morality and new reproductive technology in Lebanon. Journal of the Royal Anthropological Institute, vol. 14, n 1, 2008, pp.153-169.

. The modernity of milk kinship. Social Anthropology, vol. 15, $\mathrm{n}^{\circ} 3,2007 \mathrm{a}, \mathrm{pp} .1-18$.

. Closeness in the age of mechanical reproduction: Debating kinship and biomedicine in Lebanon and the Middle East. Anthropological Quarterly, vol. 80, n 2, 2007b, pp.379-402.

. Children of the revolution: Ayatollah Khamene'i's "liberal" views on in vitro fertilization. British Journal of Middle Eastern Studies, vol. 34, n³, 2007c, pp.287-303.

. Kinship, propriety and assisted reproduction in the Middle East. Anthropology of the Middle East, vol. 2, n²1, 2007d, pp.71-91.

- Shiite perspectives on kinship and new reproductive technologies. ISIM Review 17, 2006a, pp.26-27.

Islam, kinship and new reproductive technology. 
Anthropology Today 22, 2006b, pp.17-20.

GuPTA, J. A. New Reproductive Technologies, Women's Health and Autonomy: Freedom or Dependency?. Nova Deli, Sage, 2000 [IndoDutch Series on Development Alternatives-25].

HAELYON, Hilla. "Longing for a child": Perceptions of motherhood among Israeli-Jewish women undergoing in vitro fertilization (IVF) treatments. Nashim: Journal of Women's Studies \& Gender Issues 12, 2006, pp.177-203.

HANDWERKER, L. The politics of making modern babies in China: Reproductive technologies and the "new" eugenics. In: INHORN, M. C. e VAN BALEN, F. (orgs.) Infertility around the Globe. California, University of California Press, 2002, pp.193-214.

HÖRBST, Viola. Male infertility in Mali: Kinship and impacts on Biomedical Practice in Bamako. In: BROCKOPP, J. E. e EICH, T. (orgs.) Muslim medical ethics: From theory to practice. Columbia, University of South Carolina Press, 2008, pp.118-137.

Infertility and in-vitro fertilisation in Bamako, Mali: Women's experience, avenues for solution and social contexts impacting on gynaecological consultations. Curare 29, 2006, pp.35-46.

. Women, infertility and means for solution in urban Mali. Journal of Gender Studies 2 (1), 2004, pp.1-10.

INHORN, M. C. (org.) Reproductive Disruptions: Gender, Technology, and Biopolitics in the New Millennium. Nova York, Berghahn, 2007a.

Masturbation, semen collection and men's IVF experiences: Anxieties in the Muslim world. Body \& Society, vol. 13, n 3, 2007b, pp.37-53.

. Making Muslim babies: IVF and gamete donation in Sunni versus Shi'a Islam. Culture, Medicine and Psychiatry, vol. 30, $\mathrm{n}^{\circ} 4$, 2006a, pp.427-50.

. "He won't be my son": Middle Eastern Muslim men's discourses of adoption and gamete Donation. Medical Anthropology Quarterly, vol. 20, 2006b, pp.94-120.

. Fatwas and ARTs: IVF and gamete donation in Sunni v. Shi'a Islam. Journal of Gender, Race and Justice, vol. 9, 2006c, pp.291-317. 
Islam, IVF, and everyday life in the Middle East: the making of Sunni versus Shi'ite test-tube babies. Anthropology of the Middle East, vol. 1, 2006d, pp.37-45.

Middle Eastern masculinities in the age of new reproductive technologies: male infertility and stigma in Egypt and Lebanon. Medical Anthropology Quarterly 18, 2004, pp.162-182.

. Local babies, global science: Gender, religion and in vitro fertilisation in Egypt. Nova York/Londres, Routledge, 2003a.

. Global infertility and the globalization of new reproductive technologies: Illustrations from Egypt. Social Science and Medicine, vol. 56, no 9, 2003b, pp.1837-52.

e BHARADWAJ, Aditya. Reproductively disabled lives: infertility, stigma, and suffering in Egypt and India. In: INGSTAD, B. e WHYTE, R.S. (orgs.) Disability in local and global worlds. Berkeley, University of California Press, 2007, pp.78-106.

e BIRENBAUM-CARMELI, D. Assisted reproductive technologies and culture change. Annual Review of Anthropology, vol. 37, 2008, pp.177-96.

Male infertility, chronicity, and the plight of Palestinian men in Israel and Lebanon. In: MANDERSON, L. e SMITH-MORRIS, C. (orgs.) Chronic conditions, fluid states: Globalization and the anthropology of illness. New Brunswick-NJ, Rutgers University Press, 2009.

KAHN, Susan M. Making technology familiar: Orthodox Jews and infertility support, advice, and inspiration. Culture, Medicine and Psychiatry 30, 2006, pp.467-80.

. Rabbis and reproduction: The uses of new reproductive technologies among ultraorthodox Jews in Israel. In: INHORN, M. C. e VAN BALEN, F. (orgs.) Infertility around the Globe. California, University of California Press, 2002, pp.283-97.

- Reproducing Jews: A cultural account of assisted reproduction in Israel. Durham/Londres, Duke University Press, 2000.

MEHTA, Bhamini e KAPADIA, Shagufa. Experiences of childlessness in an Indian context: A gender perspective. Indian Journal of Gender Studies 15 (3), 2008, pp.437-460. 
ROBERTS, E. F. S. Extra embryos: The ethics of cryopreservation in Ecuador and elsewhere. American Ethnologist, vol. 34, n ${ }^{\circ}$ 1, 2007, pp.181-199.

SIMPSON, Bob. Localising a brave new world: New reproductive technologies and the politics of fertility in contemporary Sri Lanka. In: UNNITHAN-KUMAR, M. (org.) Human Reproduction, Medical Technologies and Health. Oxford, Berghahn, 2004a.

- Acting ethically, responding culturally: Framing the new reproductive and genetic technologies in Sri Lanka. The Asia Pacific Journal of Anthropology, vol. 5, n 3, 2004b, pp.227-243.

TEMAN, E. The medicalization of "nature" in the "artificial body": Surrogate motherhood in Israel. Medical Anthropology Quarterly, vol. 17, n 1, 2003a, pp.78-98.

. "Knowing" the surrogate body in Israel, In: CoOK, R.; Sclater, S.D. e KAGANAS, F. (orgs.) Surrogate Motherhood: International Perspectives. Oxford, Hart, 2003b, pp.261-279.

. Birthing a mother: The surrogate body and the pregnant self. Berkeley, California, University of California Press, 2010.

TREMAYNE, Soraya. The determinant factors of egg, sperm and embryo donation in Iran: Religion, donors and recipients or the medical practitioners? In: INHORN, M. e BIRENBAUM-CARMELI, D. (orgs.) Assisting reproduction, testing Ggenes: Global encounters with new biotechnologies. Oxford, Berghahn, 2009 [no prelo].

. Not all Muslims are luddites. Anthropology Today 22 (3), 2006, pp.1-2.

\section{Outros trabalhos relacionados - antropologia}

BAMFORD, Sandra e LEACH, James. (orgs.) Kinship and beyond: The genealogical model reconsidered. Oxford, Berghahn Books, 2009.

BESTARD, J. Kinship and the New Genetics. The Changing Meaning of Biogenetic Substance. Social Anthropology 12 (3), 2004a, pp.253-63.

- Tras la biología: La moralidad del parentesco y las nuevas tecnologías de reproducción. Barcelona, Publicacions i Edicions de la Universitat de Barcelona, 2004b. 
A Antropologia e o advento da Fertilização In Vitro no Reino Unido

CAdoret, A. Des Parents comme les autres. Homosexualité et parenté. Paris, Odile Jacob, 2003.

CARSTEN, Janet. After kinship. Cambridge, Cambridge University Press, 2004.

Knowing where you've come from: Ruptures and Continuities of time and kinship in narratives of adoption Reunions. Journal of the Royal Anthropological Institute (N.S.) 6, 2000a, pp.637-53.

. (org.) Cultures of relatedness: New approaches to the study of kinship. Cambridge, Cambridge University Press, 2000b [Conference realizada em Edinburgo, 1996].

COPEMAN, Jacob. (org.) Blood/Politics/Value: An anthropology of excorporated blood in the bioeconomy. Número Especial de Body and Society [no prelo].

FRANKLIN, Sarah. Stem cells R us: Emergent life forms and the global biological. In: ONG, A. e COLLIER, J. (orgs.) Global assemblages: Technology, politics, and ethics as anthropological problems. Malden MA, Blackwell Publishers, 2005.

e ROBERTS, Celia. Born and made: An ethnography of preimplantation genetic diagnosis. Princeton, Princeton University Press, 2006.

Jolly, Margaret e KalPANA, Ram. (orgs.) Borders of being: Citizenship, fertility and sexuality in Asia and the Pacific. Ann Arbor, University of Michigan Press, 2000.

Howell, Signe. The kinning of foreigners: Transnational adoption in a global perspective. Oxford/Nova York, Berghahn Books, 2006.

and MARRE, Diana. To kin a foreign child in Norway and Spain: The Achievement of resemblances and belonging. Ethnos 71(3), 2006, pp.293-316.

- Changes in moral values about childhood: Adoption legislation in Norway and USA. Social Analysis 50 (4), 2006.

KONRAD, Monica. Narrating the new predictive genetics: Ethics, ethnography and science. Cambridge, Cambridge University Press, 2005b. 
MODELL, Judith S. A sealed and secret kinship: The culture of policies and practices in American adoption. Nova York, Berghahn Books, 2002.

SIMPSON, Bob. Impossible gifts: Bodies, Buddhism and bioethics in contemporary Sri Lanka. Journal of the Royal Anthropological Institute (N.S.) 10 (4), 2004, pp.839-859.

TAYLOR, Janelle; LAYNE, Linda e WOZNIAK, Danielle Consuming motherhood. New Brunswick, Rutgers University Press, 2004.

TREMAYNE, Soraya. Managing reproductive life: Cross-cultural themes in fertility and sexuality. Oxford, Berghahn Books, 2002.

Wade, P. (org.) Race, Ethnicity and Nation in Europe: Perspectives from Kinship and Genetics. Nova York/Oxford, Berghahn Books, 2008.

Outras obras sobre TRA e relacionadas, não antropologia, fora da Europa e dos EUA (bibliografia compilada por Merve Demircioglu)

BiRENBAUM-CARMELI, D. Contested surrogacy and the gender order: An Israeli case study. Journal of Middle East Women's Studies, vol. 3, 2007, pp.21-44.

Cheaper than a newcomer: On the social production of IVF policy in Israel. Sociology of Health and Illness 26, 2004, pp.897-924.

e CARMELI, Y.S. Physiognomy, familialism and consumerism: References among Jewish Israeli recipients of donor insemination. Social Science and Medicine, vol. 54, 2002a, pp.363-76.

; CARMELI, Y.S., e YAVETZ, H. Secrecy among Israeli recipients of donor insemination. Politics and the Life Sciences, vol. 19, $\mathrm{n}^{\circ} 1$, 2000, pp.69-76.

BOERMA, J.T., e Mgalla, Z. (orgs.) Women and Infertility in Sub-Saharan Africa: A multidisciplinary perspective. Amsterdam, R. Trop/Inst. KIT, 2001.

DAAR, A.S. e MERALI, Z. Infertility and social suffering: The case of ART in developing countries. In: VAYENA, E.; ROWE, P.J. e GRIFFIN, P.D. (orgs.) Current Practices and Controversies in Assisted Reproduction. Genebra, WHO, 2001. 
A Antropologia e o advento da Fertilização In Vitro no Reino Unido

DINIZ, D. New reproductive technologies, ethics and gender: The legislative process in Brasil. Developing World Bioethics, vol. 2, $\mathrm{n}^{\circ} 2$, 2002, pp.144-58.

DisSANAYAKE, V.H.W.; SiMPSON, R. e JAYASEKARA, R.W. Attitudes towards the new genetic and assisted reproductive technologies in Sri Lanka: A preliminary report. New Genetics and Society, vol. 21, $\mathrm{n}^{\circ} 1$, 2002, pp.65-74.

GuilHELM, D. New reproductive technologies, ethics and legislation in Brasil: a delayed debate. Bioethics, vol. 15, n 3, 2001, pp.218-30.

HASHILONI-DOLEV, Y. e SHKEDI, S. On new reproductive technologies and family ethics: Preimplementation genetic diagnosis for sibling donor in Israel and Germany. Social Science and Medicine, vol. 65, 2007, pp.2081-92.

HoLLOS, Marrida. Profiles of infertility in Southern Nigeria: Women's voices from Amakiri. African Journal of Reproductive Health 7, 2003, pp.46-56.

NAHMAN, M. Embryos are our babies: Condensing the body in Israeli ova donation. In: EDWARDS, J.; HARVEY, P. e WADE, P. (orgs.) Technologized images, technologized bodies: Anthropological approaches to a new politics of vision. Oxford/Nova York, Berghahn, 2008.

Materialising Israeliness: Difference and mixture in transnational ova donation. Science as Culture, vol. 15, $\mathrm{n}^{\circ}$ 3, 2006, pp.199-203.

. Making more disposable people, reflections on biosociality in Israeli egg donation. In: GIBBON, S. e NovAS, C. (orgs.) Genetics, biosociality and the social sciences making biologies and identities. Londres, Routledge, 2000.

RICHARDS, S.C. "Spoiling the womb": Definitions, aetiologies and responses to infertility in North West Province, Cameroon. African Journal of Reproductive Health, vol. 6, 2002, pp.84-94.

SAMANI, R. O. et alii. Access to fertility treatments for homosexual and unmarried persons, through Iranian law and Islamic perspective. Royal Inst. Iranian Journal of Fertility and Sterility, vol. 1, n 3, 2007, pp.127-130. 
SIMPSON, Bob. Ethical regulation and the new reproductive technologies in Sri Lanka: Perspectives of ethics committee members. Ceylon Medical Journal 46 (2), 2001, pp.54-57.

VAN RoOIJ, Floor B.; VAN BALEN, Frank e HeRManNS, Jo M. A. The experiences of involuntarily childless Turkish immigrants in the Netherlands. Qualitative Health Research 19 (5), 2009, pp.621-632.

WIDGE, A. Sociocultural attitudes towards infertility and assisted reproduction in India. In: VAYENA, E.; ROWE, P.J. e GRIFFIN, P.D. (orgs.) Current Practices and Controversies in Assisted Reproduction. Genebra, WHO, 2002. 